$$
\begin{gathered}
\text { 미니돼지 및 일반 돼지의 임신기, 분만 및 포유기 중의 모돈의 행동학적 } \\
\text { 특성 비교 }
\end{gathered}
$$

강경원 · 최영환 · 김광호 · 김유용*

서울대학교 농업생명과학대학 농생명공학부

\title{
The Comparison of the Behavior between Miniature Pigs and Conventional Sows during Gestation to Lactation Period
}

\author{
Kyung Won Kang, Young Hwan Choi, Kwang Ho Kim and Yoo Yong Kim* \\ School of Agricultural Biotechnology, Seoul National University
}

\begin{abstract}
This study was conducted to compare the aspects of behavior between miniature pigs and conventional sows during gestation and lactation periods. Miniature pigs and conventional sows at 3 parity were used in this experiment with 4 pigs per treatment. The behavioral patterns and stereotyped behaviors were observed on day 60 and 90 of gestation, at farrowing, and on day 10 of lactation before and after the feeding. On 60 and 90 days of pregnancy, both treatments showed the tendency of frequent lateral lying rather than other postures. On ventral lying, eating and drinking, miniature pigs spent more time than conventional pigs at day 90 of gestation $(\mathrm{P}<0.01, \mathrm{P}=0.0539, \mathrm{P}<0.05$, respectively). The occurrence of stereotyped behaviors included bar biting and bar mouth chewing. At 90 day of pregnancy was observed, conventional pigs was higher than miniature pigs $(\mathrm{P}<0.05)$. At farrowing, miniature pigs spent more time on ventral lying, standing and walking than conventional sows $(\mathrm{P}<0.05)$, however, there were more frequency of drinking and eating. And on day 10 of lactation, there was no significant difference in stereotyped behaviors between miniature pigs and conventional sows. In conclusion, miniature pigs were generally more sensitive than conventional sows although sows were reared in stall during gestation and lactation period and the behavioral pattern during lactating period showed the similarity between miniature pigs and conventional sows for protection of nursing pigs. In consideration of the general reproductive performance of conventional sows, the high sensitivity and stress of miniature pigs did not affect the reproductive performance of miniature pigs.
\end{abstract}

(Key words : Conventional sows, Miniature pig, Behavior pattern, Stereotyped behavior)

$$
\text { 서 론 }
$$

바이오 장기란 생명공학을 응용하여, 각막 - 연골 - 피부 · 혈관 · 간 · 심장 · 폐 · 췌장 · 신장 등 인간생체의 장기와 같은 기능을 갖 는 기기를 인공적으로 만들어 인간의 장기를 대체하거나, 질병을 치료할 목적으로 생체 내에 이식하는 이종 장기를 총칭한다. 이는 기능을 잃은 인간의 조직과 장기를 복원 - 재생 - 대체하기 위하여 다른 동물의 세포와 장기를 개발한 뒤 이를 인간 체내에 이식하는 기술까지 지칭한다.

바이오 장기와 같은 장기 이식을 필요로 하는 환자 수는 매년 증가 추세에 있으나, 사람을 통해서 이루어지는 공급은 원활하지 않으며, 국내 기준으로 살펴보았을 때 장기 이식자 수는 시간이 지 남에 따라서 큰 증가를 보이지 않으며 매년 비슷한 수준을 나타내 고 있음이 이를 반영한다(정민국 등, 2006). 따라서 매년 증가하는
이식용 장기의 높은 수요를 충당하기 위한 하나의 대안으로 동물을 이용한 이종간 장기 이식이 대두되었으며, 인공 장기보다 더 큰 잠 재적인 시장성과 함께 그에 따른 연구가 전 세계적으로 활발히 이 루어지고 있는 실정이다.

이종 장기 이식을 위한 동물로써 여러 동물을 대상으로 하여 조 사가 이루어졌고, 근래에 들어 성체가 되었을 때 성인과 비슷한 체 중을 지니는 미니돼지가 가장 유력한 후보로 떠오르며 그에 관한 연구가 많이 이루어지고 있다. 미니돼지는 종별로 차이가 있지만 생시 체중이 $0.4 \sim 0.6 \mathrm{~kg}, 12$ 개월령 체중이 $25 \sim 30 \mathrm{~kg}, 24$ 개월령 성 체 기준 체중 $45 \sim 55 \mathrm{~kg}$ 을 보이며 일반 돼지의 체중에 비해 가볍 다. 하지만 번식 생리에 있어서는 일반 돼지와 유사하며, 임신 기 간은 111 114일, 성 성숙 기간은 생후 6 8개월, 복당 산자수는 7 9두를 보이고 있다.

이러한 미니돼지는 1) 인체와 체중이 비슷하기 때문에, 인체와

* Corresponding author: Yoo Yong Kim, College of Agriculture and Life Science, Seoul National University, Seoul 151-921, Korea. Tel: +82- 2-880-4801, Fax: +82-2-878-5839, E-mail: yooykim@snu.ac.kr 
비슷한 크기의 장기를 가지고, 2) 다산성으로 번식 효율이 높고, 3) 오랜 기간 가축으로써 사육되어 왔으며, 4) 잡식성인 돼지가 사람 과의 생리학적 구조가 비슷하여 이종 장기 이식에 가장 적절하다고 할 수 있다(Heo와 Lee, 2005). 미니돼지에 대한 연구 분야는 사 람의 당뇨병과 같은 질병이나 인체의 대사 및 소화 연구를 위한 실 험 동물 모델 등으로 국한되어 있으며 (Anzenbacherová 등, 2003; Larsen과 Rolin, 2004; Shim 등, 2006), 바이오 장기 공급원으로 서 미니돼지를 대상으로 한 연구는 일반 돼지와의 혈액 성상 비교 나 및 바이러스성 유전자 탐색 등으로 기초적인 연구가 시작되고 있는 실정이다(Park 등, 2006; Lee 등, 2006). 이러한 연구는 이 종 장기 동물로서의 하나의 가능성을 고려한 연구에 국한될 뿐, 안 정적인 공급을 목적으로 한 미니돼지의 생산성과 관련된 연구가 이 루어지지 않고 있는 실정이다. 따라서 미니돼지 모돈의 생산성을 높이기 위한 번식 생리 및 영양적인 정보는 외국의 사료 회사 및 미니돼지 판매 회사를 중심으로 한 사료 배합비 및 판매 정보에 국 한되어 있을 정도로 미비하며 (Testdiet, Mazuri, Labdiet 등), 미 니돼지를 위한 번식돈 사양 관리 방법은 일반 돼지의 번식돈의 그 것과 큰 차이를 보이지 않고 있다.

이는 미니돼지를 대상으로 한 번식 생리 연구가 전무한 실정인데 다가, 돼지라는 관점에서 미니돼지의 기본적인 번식 생리 자료가 일반 돼지를 대상으로 실시한 번식 생리 연구 결과를 바탕으로 이 루어졌기 때문이다. 그로 인하여 미니돼지의 번식 사양 관리는 미 니돼지를 위한 맞춤형 사양 관리이라고 하기에는 부족함이 있으며, 일반 돼지와 미니돼지의 번식 행동 특성을 고려한 사양 관리가 필 요한 실정이다.

이에 따라 본 연구는 미니돼지 및 일반 돼지의 모돈을 대상으로 하여 임신기 및 포유기 동안의 행동 특성 및 생리적 행동을 관찰하 여, 번식 성적과 비교하였다. 그에 따라 바이오 장기 생산에 사용 하게 될 미니돼지의 번식 생리 특성을 이해하고 높은 자돈 생산성 을 위한 사양 관리 확립을 위한 기초적인 연구 자료를 얻고자 실시 하였다.

\section{재료 및 방법}

\section{1. 실험 동물 및 설계}

미니돼지 및 일반 모돈의 임신기 및 포유기간 중의 행동적 특징 을 알아보기 위하여, 미니돼지 모돈 및 일반 경산돈을 3 산차에서 각 4 두씩 공시하였다. 본 실험에 사용된 미니돼지는 Yucatan, Native Pig, Pigmy Pig 및 Miniature Pot Belly 종을 이용하여 cross breeding 및 back cross breeding을 통하여 육종-번식생산된 실험용 돼지로, $\mathrm{PWG}$ 사에서 공급받아 자연 종부를 통하여 교배를 실시하였다. 또한 일반 돼지는 2원 교잡종(Yorkshire $\times$ Landrace)으로 Duroc의 정액을 사용하여 인공 수정으로 교배를 실시하였으며, 두 처리구의 임신 여부는 종부 후 21 일령 전후의 재 발정 확인과 35일령에 임신진단기(Easy Scan, Dong-Jin BLS
Co., Ltd., Korea)를 이용하여 확인하였다.

미니돼지 처리구는 임신기부터 분만 - 포유기까지 반슬랏 형태의 콘크리트 평사 $\left(0.90 \times 1.15 \mathrm{~m}^{2}\right)$ 에서 사양하였으며 건식 사료 급여 형태로 하루에 2회씩 (08:00 및 17:00; 회당 $1,000 \mathrm{~g}$ ) 총 $2,000 \mathrm{~g}$ 의 임신돈 사료를 제한급여 하였으며, 음수는 실험 종료 시점 까지 무제한 급여를 실시하였다.

일반 돼지 처리구는 임신기에는 콘크리트 바닥의 임신모돈 스톨 $\left(2.15 \times 0.6 \mathrm{~m}^{2}\right)$ 에서 사양을 실시하며 반건식 형태로 사료를 하루에 2 회씩 $(08: 00$ 및 $17: 00$; 회당 $1,200 \mathrm{~g})$ 총 $2,400 \mathrm{~g}$ 의 임신돈 사료를 제한급여 하였으며, 분만 - 포유기에는 플라스틱 슬랏의 분만틀 (돈 방 $-2.5 \times 1.8 \mathrm{~m}^{2}$, 분만틀 $\left.-2.2 \times 0.6 \mathrm{~m}^{2}\right)$ 에서 반건식 형태로 사료 급여는 자유 급이를 실시하였다.

\section{2. 조사 항목 및 방법}

\section{(1) 조사 항목 및 방법}

녹화용 비디오 $(\mathrm{CCTV})$ 를 이용하여 임신 및 포유 기간 중 일반 돼지 및 미니돼지의 행동을 관찰하였으며, 녹화된 자료를 바탕으로 한 모돈의 일반 행동 양상 및 정형 행동 (stereotyped behaviors) 조사는 다음과 같이 구분하여 실시하였다 $(\mathrm{Kim}$ 등, 2003). 일반 행동 양상은 옆으로 누운 자세 (lateral lying), 앞으로 엎드린 자세 (ventral lying), 개가 앉은 것과 같은 앉은 자세 (sitting), 서 있는 자세(standing), 걷는 동작(walking), 음수 동작(drinking) 및 사 료 섭취 동작(eating)으로 구분하였으며, 각 행동을 보이는 시간을 측정하여 총 지속 시간의 백분율 $(\%)$ 로 나타내었다. 또한 정형 행 동 조사는 벽 핱기 (wall licking), 헛 씹기(vacuum chewing, 입 속이 비어있는 상태에서 씹는 동작을 반복), 쇠 물기 (bar biting), 코로 바닥 문지르기 (floor snout rubbing), 바닥 핝기 (floor licking), 머리 흔들기 (head weaving) 및 쇠 씹기 (bar mouth chewing)로 나누고 이들 각 정형 행동의 총 빈도와 각각의 빈도를 조사하였다. 일반 행동 양상 및 정형 행동에 있어서 동작의 대표는 다음과 같이 구분되었다(Fig. 1).

또한 이러한 행동 특성의 차이가 포유 능력에 있어서 어떠한 영 향을 미치는지 알아보기 위하여 번식 성적을 기반으로 포유 능력을 조사하였다. 번식 성적의 조사 항목은 복당 산자수 (litter size), 사 산(stillborn), 미이라 (mummy), 실산자수(born alive)를 조사하였 으며, 포유 능력은 21 일간의 포유 기간을 거친 후의 이유 두수 (alive at weaning), 압사 두수(crushing) 및 포유 주령 별 일당 증 체량을 조사하였다.

\section{(2) 조사 시기}

측정 시기는 크게 임신기, 분만 시점 및 포유기로 구분하였으며, 임신기에는 종부 후 60 일 및 90 일 경과 시점에 오전 사료 급여 시 점부터 익일 오전 사료 급이 전까지 24시간 동안 일반 행동 양상 및 정형 행동의 빈도를 측정하였다. 또한 분만시에는 분만 전 젖 내림 현상으로 분만 시기를 추정하여, 분만 2시간 전부터 후산 배 


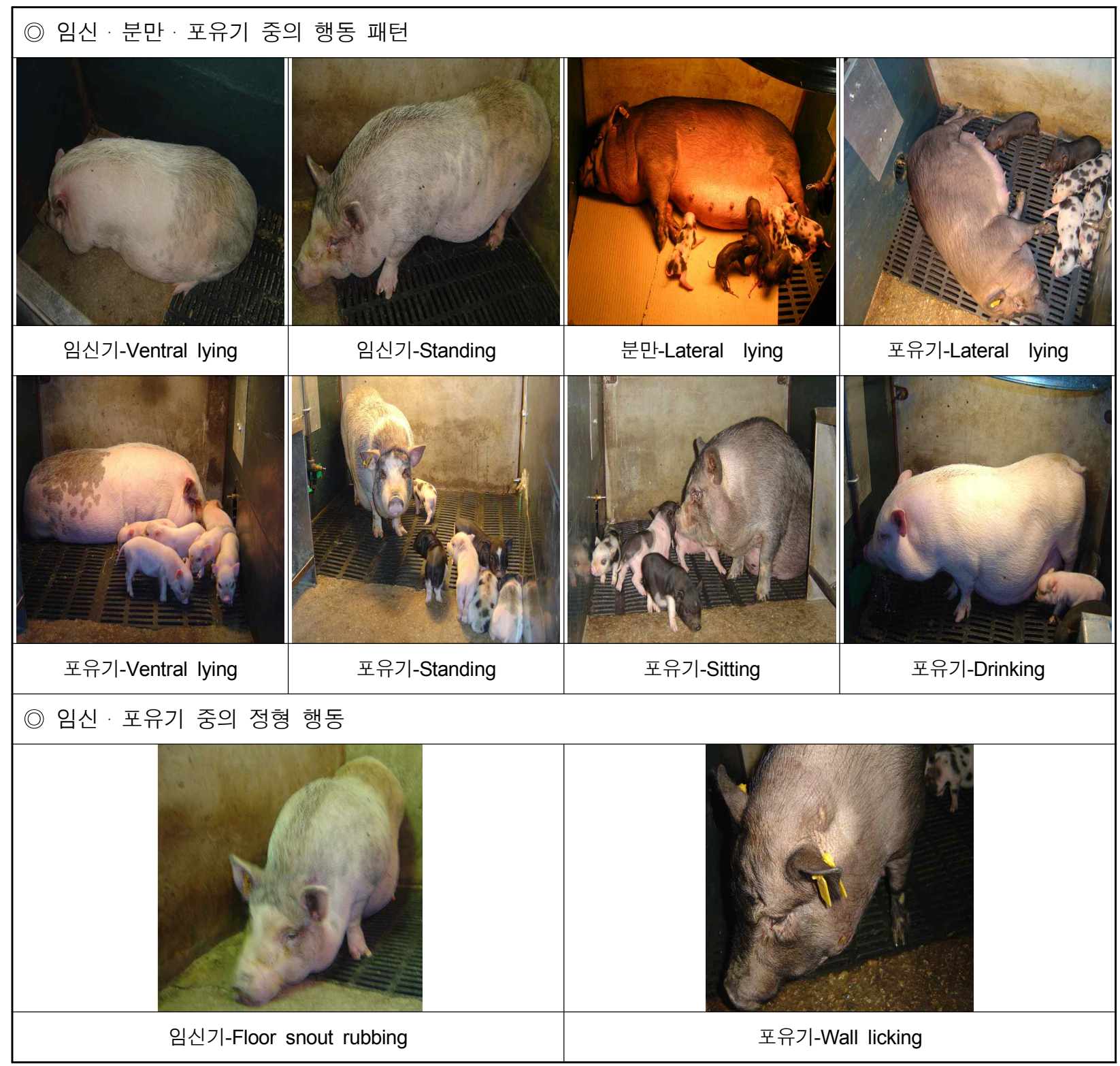

Fig. 1. The pattern of behaviors miniature pigs during the gestating to lactating period.

출 시점까지 약 6시간 동안 일반 행동 양상을 분석하였으며, 포유 기에는 분만 10 일 후, 오전 사료 급여 1 시간 전부터 사료 급여 1.5 시간이 경과한 2.5 시간 동안 일반 행동 양상과 정형 행동 빈도를 조사하였다.

\section{3. 통계분석}

통계분석은 SAS(SAS Institute, 2008)의 일반 선형 모형 (general linear model; GLM)을 이용하여 수집된 자료에 대한 유 의성 검정을 실시하였으며, 최소 유의차(LSD) 검정법에 의해 처리 한 결과를 비교하였다.

\section{결과 및 고찰}

\section{1. 임신기}

\section{(1) 행동학적 양상}

임신기 동안의 미니돼지 및 일반 돼지의 일반 행동 양상은 Table 1에 나타난 바와 같다. 임신기 동안 모돈이 나타내는 행동 양상의 가장 큰 특징은 옆으로 누운 자세(lateral lying)가 두 종에 상관없이 가장 높게 나타난 것이며, 구체적으로는 임신 60 일령에는 각 행동 양상에 있어서 유의적인 차이를 보이지 않았다. 또한 임신 90일령에는 옆으로 누운 자세 (lateral lying)로 보내는 시간이 일반 돼지가 미니돼지보다 유의적인 차이를 보이며 길었다 $(\mathrm{P}<0.01)$. 
Table 1. The comparison of the behavior between miniature pigs and conventional sows during the gestation period

\begin{tabular}{lccc}
\hline \multirow{2}{*}{ Items } & \multicolumn{2}{c}{ Treatments } & \\
\cline { 2 - 3 } & $\begin{array}{c}\text { Miniature } \\
\text { pig }^{1)}\end{array}$ & Sow $^{2)}$ & \\
\hline \hline Gestation D-60 & & & \\
Lateral lying & 67.76 & 73.22 & 1.49 \\
Ventral lying & 22.34 & 18.41 & 1.04 \\
Sitting & 0.87 & 0.87 & 0.12 \\
Standing & 0.42 & 0.76 & 0.12 \\
Walking & 5.34 & 3.82 & 0.43 \\
Drinking & 1.51 & 1.48 & 0.11 \\
Eating & 1.78 & 1.44 & 0.38 \\
\hline Gestation D-90 & & & \\
Lateral lying & $59.72^{\mathrm{B}}$ & $74.94^{\mathrm{A}}$ & 3.02 \\
Ventral lying & $29.17^{\mathrm{A}}$ & $16.24^{\mathrm{B}}$ & 2.51 \\
Sitting & 4.04 & 3.32 & 0.48 \\
Standing & 1.07 & 2.20 & 0.27 \\
Walking & 1.52 & 1.48 & 0.30 \\
Drinking & 2.17 & 0.93 & 0.33 \\
Eating & $2.31^{\mathrm{a}}$ & $0.91^{\mathrm{b}}$ & 0.34 \\
\hline
\end{tabular}

${ }^{1)}$ Miniature pig.

${ }^{2)}$ Conventional pigs.

3) Standard error of mean.

${ }^{\mathrm{A}, \mathrm{B}}$ Means with different superscripts in the same row significantly differ $(\mathrm{P}<0.01)$.

a,b Means with different superscripts in the same row significantly differ $(\mathrm{P}<0.05)$.

임신 모돈이 임신 중기 (임신 60일) 및 후기 (임신 90일) 중 두 번째로 오랜 시간을 보내는 앞으로 엎드린 자세(ventral lying)에서 는 임신 60 일령에서는 미니돼지가 일반 돼지 보다 높은 경향을 보 였으며 $(\mathrm{P}=0.10)$, 임신 90 일령에서는 미니돼지가 일반 돼지보다 유 의적으로 높았다 $(\mathrm{P}<0.01)$. 또한 앉아 있는 자세 (sitting)는 임신 60 및 90 일령에서 미니돼지가 일반 돼지보다 높거나 같게 나타났 으나, 유의적인 차이를 보이지 않았으며, 서 있는 자세(standing)는 일반 돼지가 미니돼지보다 높은 경향을 보였다 $(\mathrm{P}=0.07)$. 걷는 동 작 (walking)은 임신 60일에 미니돼지가 펜 사육의 영향으로 일반 돼지보다 길었으나 유의적인 차이를 보이지 않았으며, 임신 90 일령 에는 비슷한 시간을 걷는 동작 (walking)에 소비하였다.

음수 동작 (drinking)으로 보내는 시간의 비율은 임신 60 및 90 일령에 유의적인 차이를 보이지 않았지만, 임신 90 일령에 미니돼지 가 약 $1 \%$ 정도 더 높은 경향을 보였다 $(\mathrm{P}=0.0539)$. 사료 섭취 동 작 (eating)에 있어서 소요하는 시간은 임신 90 일령에서 미니돼지가 약 $1.4 \%$ 더 길었으며, 유의적인 차이를 보였다 $(\mathrm{P}<0.05)$.

임신 기간에 있어서 옆으로 누운 자세 (lateral lying) 및 엎드린
자세 (ventral lying)의 합이 두 종 모두 $90 \%$ 에 가까운 수치를 보 이며, 임신 기간 중 대부분의 시간은 누운 자세 (lying)로 있다는 것을 알 수 있다. 이는 최소의 대사 활동으로 체내 영양소 손실을 최소화하기 위함으로 사료되며, 임신돈의 행동을 조사한 여러 연구 에서도 누운 자세가 행동 중의 대부분을 차지하였다고 보고되었 다 (McGlone과 Fullwood, 2001: Kim 등, 2003).

임신 기간이 길어짐에 따라 미니돼지가 상대적으로 음수 동작 (drinking) 및 사료 섭취 동작 (eating)이 증가하는 것은 임신기의 스트레스로 주위 환경에 대해 예민해져 스트레스가 가중되기 때문 에 발생한 것으로 판단된다. 이는 음수 동작 (drinking)이 높은 스 트레스 해소를 위한 방안으로 이루어진다는 연구 결과와 일치한다 (Kim 등, 2003). 하지만 상대적으로 넓은 펜 사육을 실시한 미니 돼지가 좁은 스톨 사육을 실시한 일반 돼지보다 높은 수준의 음수 동작 (drinking)을 보이는 것은, 음수 동작 (drinking)이 스톨 수용 에서 나타나는 제한된 동작의 답답함을 해소하기 위함이라고 한 연 구 결과와 상반된다(Kim 등, 2003).

\section{(2) 정형 행동 (Stereotyped behavior)}

임신돈의 다양한 정형 행동을 Table 2에 나타내었다. 임신 기간 이 길어짐에 따라서 정형 행동을 하는 빈도는 두 처리구 모두 증가 하였으며, 상대적으로 행동에 제약이 있는 임신 스톨에서 사육된 일반 돼지의 증가치가 미니돼지에 비해서 더 높은 경향을 보였으 며, 임신 90 일령에 정형 행동의 총 빈도에서 일반 돼지가 미니돼지 보다 약 34회 더 많은 빈도를 나타내었다 $(\mathrm{P}<0.05)$.

벽 핝기 (wall licking) 및 헛 씹기 (vacuum chewing)는 임신 60 일령에는 두 처리구 간 유의적인 차이를 보이지 않았으나, 임신 90 일령에는 일반 돼지에서 각각 더 높은 경향을 보였다 $(\mathrm{P}=0.05$, $\mathrm{P}=0.06$ ). 임신돈의 쇠 물기 (bar biting)는 임신 60 및 90 일령에 모두 일반 돼지에서 미니돼지보다 2 3배 많은 빈도를 보이며, 유 의적으로 높았다 $(\mathrm{P}<0.05)$. 또한 임신 60 일령에는 코로 바닥 문지 르기 (floor snout rubbing)가 펜 사육을 실시한 미니돼지에서 일반 돼지보다 높은 경향을 보였으며 $(\mathrm{P}=0.05)$, 임신 90 일령에는 미니돼 지가 2 배 정도 높은 빈도를 보였다 $(\mathrm{P}<0.05)$.

바닥 핱기 (floor licking)는 임신 60일령에서 미니돼지가 일반 돼지보다 유의적으로 높은 빈도수를 보였으며 $(\mathrm{P}<0.05)$, 임신 90 일령에는 유의적인 차이를 보이지 않았다. 머리 흔들기(head weaving)는 임신 60 및 90일령에서 비슷한 빈도수를 보이며, 유의 적인 차이를 보이지 않았다. 또한 쇠 씹기 (bar mouth chewing)에 서는 일반 돼지가 미니돼지보다 7 8배 높은 빈도를 보이며, 임신 90 일령에는 일반 돼지의 쇠 씹기 (bar mouth chewing) 동작이 3.5 회 $/ 24 \mathrm{~h}$ 로 미니돼지의 0.5 회 $/ 24 \mathrm{~h}$ 보다 유의적으로 높았다 $(\mathrm{P}<0.05)$. 이와 같은 결과는 일반 돼지의 경우 임신기 동안 제한 급이가 이루어지기 때문으로, 공복감을 미니돼지에 비하여 더 많이 느끼기 때문에 나타나는 행동 형태라고 생각된다.

Wiepkema (1987)은 정형 행동을 어떠한 목적 없이, 특정 행동 을 여러 번 반복하는 것이라 정의하였고, Barnett 등(1985) 및 
Table 2. The comparison of the occurrence of stereotyped behaviors between miniature pigs and conventional sows during the gestation period

\begin{tabular}{|c|c|c|c|}
\hline \multirow[b]{2}{*}{ Items } & \multicolumn{2}{|c|}{ Treatments } & \multirow[b]{2}{*}{ SEM $^{3)}$} \\
\hline & $\begin{array}{c}\text { Miniature } \\
\text { pig }^{1)}\end{array}$ & Sow $^{2)}$ & \\
\hline \multicolumn{4}{|l|}{ Gestation D-60 } \\
\hline Total & 69.00 & 72.25 & 2.63 \\
\hline Wall licking & 8.75 & 7.00 & 0.66 \\
\hline Vacuum chewing & 33.00 & 36.00 & 1.90 \\
\hline Bar biting & $3.75^{\mathrm{b}}$ & $9.25^{\mathrm{a}}$ & 1.28 \\
\hline Floor snout rubbing & 10.25 & 6.25 & 0.99 \\
\hline Floor licking & $7.50^{\mathrm{a}}$ & $4.25^{\mathrm{b}}$ & 0.91 \\
\hline Head weaving & 5.25 & 5.25 & 0.59 \\
\hline Bar mouth chewing & 0.50 & 4.25 & 0.94 \\
\hline \multicolumn{4}{|l|}{ Gestation D-90 } \\
\hline Total & $73.25^{\mathrm{b}}$ & $107.50^{\mathrm{a}}$ & 7.69 \\
\hline Wall licking & 11.75 & 20.00 & 1.84 \\
\hline Vacuum chewing & 34.25 & 48.75 & 4.08 \\
\hline Bar biting & $7.00^{\mathrm{b}}$ & $18.75^{\mathrm{a}}$ & 2.58 \\
\hline Floor snout rubbing & $10.75^{\mathrm{a}}$ & $5.00^{\mathrm{b}}$ & 1.46 \\
\hline Floor licking & 6.25 & 8.25 & 1.24 \\
\hline Head weaving & 2.75 & 3.25 & 0.46 \\
\hline Bar mouth chewing & $0.50^{\mathrm{b}}$ & $3.50^{\mathrm{a}}$ & 0.65 \\
\hline $\begin{array}{l}\text { 1) Miniature pig. } \\
{ }^{2)} \text { Conventional pigs. } \\
{ }^{3)} \text { Standard error of mean. } \\
{ }^{a, b} \text { Means with different } \mathrm{S} \\
(\mathrm{P}<0.05) \text {. }\end{array}$ & erscripts i & ne row & antly diff \\
\hline
\end{tabular}

Fraser (1975)은 대표적인 정형 행동은 대부분 입으로 하는 동작이 라고 보고하였다. 본 실험에서도 정형 행동 중에서 헛 씹기 (vacuum chewing) 및 쇠 물기 (bar biting)와 같은 입으로 하는 정형 행동 빈도가 높게 나타나 기존 연구와 유사한 행동 양상을 보 였다. 이 중 쇠 물기(bar biting)는 스톨 사육에서 나타나는 대표적 인 정형 행동이며, 쇠 물기 (bar biting)가 나타나는 것은 스톨 사 육과 관련 있다고 한 연구 결과가 있었으며(Fraser, 1975; Caroline 등, 1995), 본 실험에서도 임신 60 및 90일에 일반 돼지 에서 쇠 물기 (bar biting) 행동이 유의적으로 높은 빈도를 나타내 그 결과가 일치하였다 $(\mathrm{P}<0.05)$.

따라서 임신 기간 동안 평사에서 사양되었던 미니돼지의 상대적 으로 낮은 정형 행동의 빈도는 사육 환경에 의한 결과인 것으로 보 이며, 상업적 모돈의 번식을 고려하였을 때, 이러한 정형 행동이 미니돼지의 번식 효율 및 성적에 있어서 큰 영향을 미치지 않는 것 으로 사료된다.

\section{2. 포유기}

\section{(1) 행동학적 양상}

분만 후 6 시간 및 분만 10 일 후 사료섭취 전후의 2.5 시간 동안 의 미니돼지 및 일반 돼지의 일반 행동 양상은 Table 3에 나타난 바와 같다. 분만 시점 전후 6시간 동안의 옆으로 누운 자세 (lateral lying) 및 앞으로 엎드린 자세 (ventral lying)는 미니돼지 및 일반 돼지 두 처리구에서 전체 행동 중의 $90 \%$ 를 차지하며 임신기와 유 사한 경향을 보였다. 옆으로 누운 자세 (lateral lying)는 일반 돼지 가 미니돼지에 비해 높은 경향을 보였으며 $(\mathrm{P}=0.05)$, 앞으로 엎드 린 자세 (ventral lying)는 미니돼지가 일반 돼지보다 유의적으로 약 $7 \%$ 높았다 $(\mathrm{P}<0.01)$. 또한 일반 돼지가 분만 시점에 있어서 앉 은 자세 (sitting)로 보내는 시간이 많은 경향을 보였으며 $(\mathrm{P}=0.05)$, 서 있는 자세 (standing) 및 걷는 행동 (walking)으로 지내는 시간 은 미니돼지보다 유의적으로 짧았다 $(\mathrm{P}<0.05)$. 그리고 음수 동작 (drinking)와 사료 섭취 동작(eating)으로 보내는 시간의 비율은

Table 3. The comparison of the behavior between miniature pigs and conventional sows during the farrowing to lactating period

\begin{tabular}{|c|c|c|c|}
\hline \multirow{2}{*}{ Items } & \multicolumn{2}{|c|}{ Treatments } & \multirow{2}{*}{$\mathrm{SEM}^{3)}$} \\
\hline & Miniature pig ${ }^{1)}$ & Sow $^{2)}$ & \\
\hline \multicolumn{4}{|c|}{ Parturition $6.0 \mathrm{~h}^{4)}$} \\
\hline Lateral lying & 60.14 & 66.90 & 1.50 \\
\hline Ventral lying & $30.37^{\mathrm{A}}$ & $23.16^{\mathrm{B}}$ & 1.47 \\
\hline Sitting & 1.90 & 3.75 & 0.42 \\
\hline Standing & $1.23^{\mathrm{a}}$ & $0.26^{\mathrm{b}}$ & 0.21 \\
\hline Walking & $1.71^{\mathrm{a}}$ & $0.24^{\mathrm{b}}$ & 0.31 \\
\hline Drinking & 1.70 & 1.80 & 0.13 \\
\hline Eating & 2.94 & 3.90 & 0.84 \\
\hline \multicolumn{4}{|c|}{ Lactation $\mathrm{D}^{-10} 2.5 \mathrm{~h}^{5)}$} \\
\hline Lateral lying & $18.59^{\mathrm{b}}$ & $24.64^{\mathrm{a}}$ & 1.49 \\
\hline Ventral lying & $34.54^{\mathrm{a}}$ & $29.19^{\mathrm{b}}$ & 1.34 \\
\hline Sitting & 2.28 & 1.36 & 0.26 \\
\hline Standing & $2.43^{\mathrm{A}}$ & $0.57^{\mathrm{B}}$ & 0.40 \\
\hline Walking & $7.43^{b}$ & $13.30^{\mathrm{a}}$ & 1.20 \\
\hline Drinking & 2.81 & 3.15 & 0.26 \\
\hline Eating & 31.92 & 27.79 & 1.36 \\
\hline \multicolumn{4}{|c|}{ 1) Miniature pig. } \\
\hline \multicolumn{4}{|c|}{ 2) Conventional pigs. } \\
\hline \multicolumn{4}{|c|}{ 3) Standard error of mean. } \\
\hline \multirow{2}{*}{\multicolumn{4}{|c|}{$\begin{array}{l}\text { 4) About } 6 \text { hours starting from } 2 \text { hours before farrowing to afterbirth. } \\
\text { 5) About } 2.5 \text { hours before from } 1 \text { hour of feeding to } 1.5 \text { hour of after } \\
\text { feeding. }\end{array}$}} \\
\hline & & & \\
\hline \multicolumn{4}{|c|}{$\begin{array}{l}\text { A,B Means with different superscripts in the same row significantly } \\
\text { differ }(\mathrm{P}<0.01) \text {. }\end{array}$} \\
\hline \multicolumn{4}{|c|}{$\begin{array}{l}\text { a,b Means with different superscripts in the same row significantly } \\
\text { differ }(\mathrm{P}<0.05) \text {. }\end{array}$} \\
\hline
\end{tabular}


두 처리간 유의적인 차이를 보이지 않았다.

분만 10 일 경과 후, 사료 급여 전후 2.5 시간 동안의 미니돼지와 일반 돼지의 행동 양상은 옆으로 누운 자세 (lateral lying) 및 앞으 로 엎드린 자세(ventral lying)가 전체 관찰 시간 중 $50 \%$ 를 넘으 며, 옆으로 누운 자세 (lateral lying)에서는 일반 돼지가, 앞으로 엎 드린 자세 (ventral lying)에서는 미니돼지가 더 많은 지속 시간을 보였다 $(\mathrm{P}<0.05)$. 또한 서 있는 자세 (standing)로 보내는 시간에서 는 미니돼지가 고도의 유의적인 차이를 보이며 일반 돼지보다 더 높았으며 $(\mathrm{P}<0.01)$, 걷는 행동 (walking)에서는 일반 돼지가 유의적 으로 더 높았다 $(\mathrm{P}<0.05)$. 앉은 자세 (sitting), 음수 동작 (drinking) 와 사료 섭취 동작 (eating)에서는 포유 10 일차에서 유의적인 차이 를 보이지 않았다.

수용 형태 및 산차와 관계없이 분만 당일 모돈은 옆으로 혹은 앞으로 엎드린 자세 (평균 22.6시간)로 하루 중 대부분을 보내는 것으로 알려져 있는데 $(\mathrm{Kim}$ 등, 2003), 본 실험에서도 분만 전후 6시간 동안 누워 있는 자세 (lying)의 지속 시간이 $90 \%$ 를 넘으며 유사한 결과를 보였다.

Cronin 등 (1991)과 Lawrence 등 (1994)이 보고한 바에 의하면 분만 공간을 분만틀 (crate)과 분만방 (pen)으로 비교한 실험에서 분 만틀에서 분만한 초산돈이 임신 기간 동안 움직임이 자유로운 분만 방에서 분만한 초산돈에 비하여 스트레스를 많이 받았다고 하였다. 또한 초산돈의 경우 움직임의 구속을 당해본 경험이 없고 분만틀에 대한 최초의 경험으로 더 많은 스트레스를 받게 되어, 옆으로 누운 자세 (lateral lying)가 많아지고 엎드린 자세(ventral lying)는 줄 어드는 행동 양상을 보인다고 보고하였다. 하지만 본 실험에서는 분만 10 일 후의 행동 양상에서 미니돼지 및 일반 돼지는 엎드린 자세 (ventral lying)가 상대적으로 더 많은 결과를 보였는데, 이는 본 실험에서 사용된 모돈이 두 처리 구 모두 3산차의 경산돈이기 때문에 분만틀이나 평사에서의 포유 경험과 및 분만 환경에 대한 적응으로 스트레스를 적게 받은 것이 주 원인으로 사료된다. 또한 미니돼지가 일반 돼지보다 누운 자세 (lying) 중 엎드린 자세 (ventral lying) 비중이 많은 것은 미니돼지의 포유가 공간이 더 넓 은 펜에서 이루어짐으로써, 행동에 제약을 덜 받게 되어 포유 기간 중 받게 되는 스트레스가 일반 돼지에 비하여 적기 때문으로 사료 된다.

Boyle 등 (2002)은 분만 후 10 일 째 서 있는 자세 (standing)로 소비한 시간은 펜 분만과 분만틀 분만은 차이가 없음을 보고하였는 데, 본 실험에서는 펜 분만을 실시한 미니돼지가 일반 돼지보다 유 의적으로 5 배 가량 높은 소비 시간을 보이며 $(2.43 \%$ vs. $0.57 \%)$ 상 반된 결과를 보였다.

\section{(2) 정형 행동}

분만 10 일 후 사료섭취 전후의 2.5 시간 동안의 미니돼지 및 일 반 돼지의 정형 행동 빈도는 Table 4에 나타난 바와 같다. 분만 후 10 일에 일어나는 정형 행동 반복 수는 두 처리에 있어서 유사 한 빈도 수를 보였으며, 헛 씹기 (vacuum chewing)가 분만 시점과
Table 4. The comparison of the occurrence of stereotyped behaviors between miniature pigs and conventional sows during the lactation period

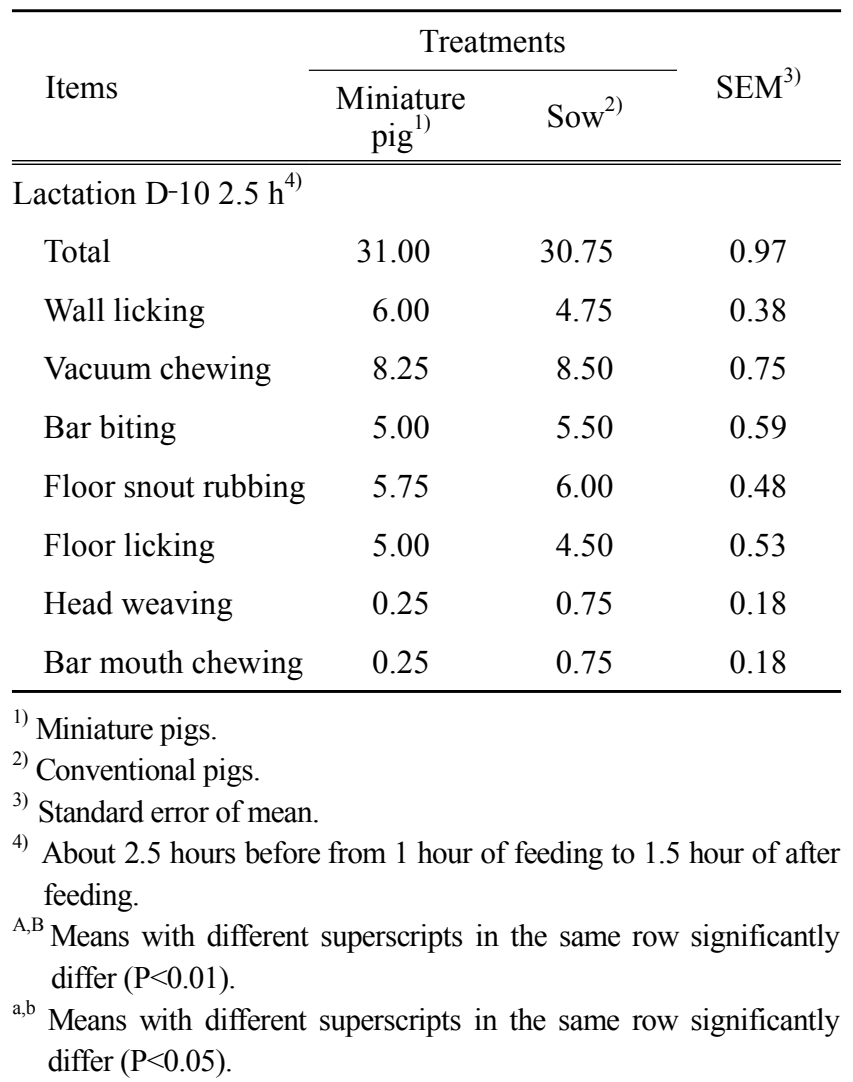

마찬가지로 가장 많은 빈도를 보였고 코로 바닥 문지르기 (floor snout rubbing), 벽 핱기 (wall licking), 쇠 물기 (bar biting) 순으 로 많이 나타났다. 포유 10 일령에서 오전 사료 급이 시점의 여러 정형 행동에서 두 처리간 유의적인 차이는 보이지 않았으며, 대체 로 비슷한 경향을 보였다.

$\operatorname{Kim}$ 등 (2003)이 실시한 임신돈의 수용 형태 및 산차에 따른 연 구에 의하면 임신기에 비하여 포유기에는 정형 행동이 줄어들었는 데, 이와 같은 결과는 포유 기간 동안 포유 자돈을 보호하기 위한 본능적인 행동 특성으로 안정을 취하기 위하여 정형 행동수가 낮아 진 것으로 보고되었으며, Jensen (1988)도 분만 후에 포유 기간이 길어질수록 모돈의 눕는 자세 (lying)가 줄어드는 경향이 있다고 보 고하였다. 포유 자돈 폐사의 $47.8 \%$ 가 압사로 인한 것임을 고려할 때 (Reese 등, 2001), 포유 기간 중 모돈은 포유 자돈의 보호를 위 해서 일반 행동 및 정형 행동에 있어서 시기에 따른 변화를 주는 것을 알 수가 있다. 따라서 포유 10 일령에 미니돼지와 일반 돼지의 눕는 자세 (lying) 및 정형 행동 빈도가 비슷한 경향을 나타내는 것 을 고려해볼 때, 미니돼지의 포유 행동의 변화는 일반 모돈의 행 동 양상 변화의 목적과 같이 포유 자돈을 보호하기 위함이라고 사 료된다. 
(3) 번식 성적

Table 5에 미니돼지 및 일반 모돈의 번식 성적을 나타내었다. 복당 산자수 및 실산자수는 유의적으로 일반 모돈이 미니돼지보다 높음을 보여주며 $(\mathrm{P}<0.01)$, 각각 4.6두로 일반 돼지가 미니돼지에 비하여 분만 성적에 있어서 높았다. 사산 및 미이라 수에 있어서는 유사한 수치를 보이며 유의적인 차이를 보이지 않았다.

압사에 있어서는 통계적인 유의차이를 보이며 $(\mathrm{P}<0.05)$, 미니돼 지가 1.7 두로 전체 실산자수 대비 $22 \%$ 의 압사율을 보였으며, 일반 돼지에 비하여 1.5 두가 많았다. 이는 이유율에 있어서 큰 차이를 보이며 미니돼지의 자돈 생산성을 떨어뜨리는 주 원인이 되었다.

Weary 등 (1996)이 보고한 실험에 의하면, 포유 자돈은 주로 모 돈의 주된 움직임 (서기, 앉기, 눕기, 구르기)에 의해 주로 압사 당 하며, 압사 방식은 분만 시설에 따라 다른 경향을 보인다. 또한 평 사에서는 옆구리로 누워있다 유방을 밑으로 하거나 유방을 밑으로 하였다가 옆구리로 눕는 등의 구르기 행동에서 분만틀보다는 더욱

Table 5. The reproductive performances between miniature pigs and conventional sows during the lactation period

\begin{tabular}{|c|c|c|c|}
\hline \multirow[b]{2}{*}{ Items } & \multicolumn{2}{|c|}{ Treatments } & \multirow[b]{2}{*}{$\mathrm{SEM}^{3)}$} \\
\hline & $\begin{array}{c}\text { Miniature } \\
\text { pig }^{1)}\end{array}$ & Sow $^{2)}$ & \\
\hline \multicolumn{4}{|l|}{ Farrowing performance } \\
\hline No. Born/litter & $8.1^{\mathrm{B}}$ & $12.7^{\mathrm{A}}$ & 0.7 \\
\hline No. Stillborn/litter & 0.3 & 0.3 & 0.1 \\
\hline No. Mummies/litter & 0.5 & 0.3 & 0.1 \\
\hline No. Born alive/litter & $7.8^{\mathrm{B}}$ & $12.4^{\mathrm{A}}$ & 0.7 \\
\hline No. Crushed pig/litter & $1.7^{\mathrm{a}}$ & $0.2^{\mathrm{b}}$ & 0.3 \\
\hline No. Alive at weaning/litter & $6.1^{\mathrm{B}}$ & $12.2^{\mathrm{A}}$ & 0.9 \\
\hline \multicolumn{4}{|c|}{ Body weight of a piglet during lactation $(\mathrm{g})$} \\
\hline Post-farrowing (24h) & $477^{\mathrm{B}}$ & $1,343^{\mathrm{A}}$ & 133 \\
\hline $7 \mathrm{~d}$ & $897^{\mathrm{B}}$ & $2,427^{\mathrm{A}}$ & 233 \\
\hline $14 \mathrm{~d}$ & $1,334^{\mathrm{B}}$ & $3,722^{\mathrm{A}}$ & 365 \\
\hline $21 \mathrm{~d}$ & $1,976^{\mathrm{B}}$ & $5,097^{\mathrm{A}}$ & 477 \\
\hline \multicolumn{4}{|c|}{ Average daily gain of a piglet during lactation $(\mathrm{g})$} \\
\hline $0 \sim 7 \mathrm{~d}$ & $60^{\mathrm{B}}$ & $154^{\mathrm{A}}$ & 15 \\
\hline $7 \sim 14 \mathrm{~d}$ & $62^{\mathrm{B}}$ & $185^{\mathrm{A}}$ & 20 \\
\hline $14 \sim 21 \mathrm{~d}$ & $92^{\mathrm{B}}$ & $197^{\mathrm{A}}$ & 16 \\
\hline $0 \sim 21 \mathrm{~d}$ & $71^{\mathrm{B}}$ & $178^{\mathrm{A}}$ & 17 \\
\hline
\end{tabular}

\footnotetext{
${ }^{1)}$ Miniature pigs.

${ }^{2)}$ Conventional pigs.

3) Standard error of mean.

${ }^{\mathrm{A}, \mathrm{B}}$ Means with different superscripts in the same row significantly differ $(\mathrm{P}<0.01)$.

${ }^{\mathrm{a}, \mathrm{b}}$ Means with different superscripts in the same row significantly differ $(\mathrm{P}<0.05)$
}

높은 압사를 보였다. 본 실험에서는 구르기에 대해서 측정을 하지 못하였으나, 분만 전후 및 포유 10 일경에 있어서 유방이 밑으로 가 있는 형태인 앞으로 엎드린 자세 (ventral lying)에서 미니돼지가 유의적으로 높았음을 고려하였을 때 구르기 행동이 빈번하게 발생 할 것으로 사료된다.

포유 자돈의 성장 성적에 있어서는 포유 전 기간 $(21$ 일 포유)에 있어서 고도의 유의성 $(\mathrm{P}<0.01)$ 을 보이며 일반 돼지가 미니돼지에 비하여 높았으며, 이는 생시 체중의 차이에 기인한 것으로 판단된 다. Cho (2006)의 연구에 의하면 이유 시점의 이유 체중이 자돈기 성장에 큰 영향을 미쳤음을 보고하였으며, 이는 성장률이 높은 자 돈 초기 체중이 성장률에 큰 영향을 미치는 것으로 사료된다.

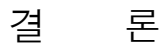

미니돼지와 일반 돼지에 있어서 경산돈의 임신기 및 포유기 동안 모돈의 행동학적 차이를 관찰하기 위하여, 일반 행동 양상 및 정형 행동 빈도 수를 비교 - 조사하였다. 본 실험을 통해 일반 행동 양상 의 결과를 보았을 때, 임신 기간이 길어짐에 따라서 미니돼지가 일 반 돼지에 비해 상대적으로 스트레스를 많이 받는 것으로 보이며, 정형 행동 빈도에 있어서 일반 돼지보다 낮은 것은 사육 환경의 차 이에 기인한 것으로 사료된다. 또한 임신 후기에 미니돼지가 받는 높은 스트레스는 주변 환경에 대한 선천적인 예민함으로 인한 것으 로 판단된다. 포유 기간에 따른 일반 행동 양상 및 정형 행동 빈도 수의 변화는 미니돼지와 일반 돼지가 유사하게 나타났으며, 이는 포유 자돈을 보호하기 위한 번식 행동 습성의 변화라고 사료된다. 결론적으로 일반 상업적 모돈의 번식 성적을 고려하였을 때, 이러 한 미니돼지의 행동 습성 변화는 일반 돼지에 비하여 다소 차이가 있으나 효율적인 번식 성적을 위한 분만틀 환경 조건 내에서라면, 미니돼지의 번식 효율 및 성적에 있어서 큰 영향을 미치지 않는 것 으로 판단되며, 이에 대해서는 미니돼지의 번식 행동을 중심으로 다양한 번식 사육 시설을 비교한 추가적인 연구가 필요하다.

$$
\text { 사 사 }
$$

본 연구는 농촌진흥청 바이오그린 21사업 (과제번호: 200704014020)의 지원에 의해 이루어진 연구 결과의 일부이며, 연구비 지원 에 감사드립니다.

\section{인 용 문 헌}

정민국, 허 덕, 김현중. 2006 , 무균 돼지 바이오 장기의 잠재 수 요 분석. 33(3):789-801

Barnett, J. L., Winfield, C. G., Cronin, G. M., Hemsworth, P. H. and Dewar, A. M. 1985. The effect of individual and group housing on behavioral and physiological responses related to the welfare of pregnant pigs. Appl. Anim. Behav. Sci. 
$14: 149-161$

Barnett, J. L., Hemsworth, P. H., Cronin, G. M., Jongman, G. M. and Hutson, G. D. 2001. A review of the welfare issues for sows and piglets in relation to housing. Aust. J. Agric. Res. $52: 1-28$.

Boyle, L. A., Leonard, F. C., Lynch, P. B. and Brophy, P. 2002 Effect of gestation housing on behaviour and skin lesions of sows in farrowing crates. Appl. Anim. Behav. Sci. 76:119-134.

Cronin, G. M., Barnett, J. L., Hodge, F. M., Smith, J. A. and McCallum, T. H. 1991. The welfare of pigs in two farrowing/lactation environments; cortisol responses of sows. Appl. Anim. Behav. Sci. 32:117-127.

Fraser, D. 1975. The effected straw on the behaviour of sows in tether stalls. Anim. Prod. 21:59-68.

Eva Anzenbacheroá, Pavel Anzenbacher, Zbyněk Svoboda, Jitka Ulrichova, Jaroslav Květina, Jana Zoulová, František Perlík and Jiřina Martíková. 2003. Minipig as a model for drug metabolism in man: comparison of in vitro and in vivo metabolism of propafeone. Biomed. Papers. 147(2):155-159.

Heo duk and Lee, P. H. 2005. Necessities and Aspect of producing Bio-Internal Organs, Korean Journal of Agricultural Management and policy. 32:559-572.

Jensen, P. 1988. Maternal behavior and mother-young inter- actions during in free-ranaing domestic pigs. Appl. Anim. Behav. Sci 20:297-308

Jeon, J. H., Kim, D. J., Han, J. H., Yeon, P. H. and Chang, H. H. 2003. Behavioral recovery of sows and behavioral development of their piglets postpartum. J. Anim. Sci. \& Technol. 45(6):1089-1096.
McGlone J. J. and Fullwood S. D. 2001. Behavior, reproduction and immunity of crated pregnant gilts: effects of high dietary fiber and rearing environment. J. Anim. Sci. 79:1466-1474.

Kim, D. H., Park, J. Y. and Woo, J. H. 2003. Effects of gestation housing and parity on the farrowing performance and behaviour of sows during the pregnancy, farrowing and lactation. J. Anim. Sci. \& Technol. 45(6):1067-1078.

Kyung, Mi Shim, Kim, Se Eun, Bae, Chun-Sik, Choi, Seok Hwa, Han, Ho Jae, Kang, Seong Soo and Park, Soo Hyun. 2006. Radio observations of alimentary tract in miniature pigs. Lab. Anim. Res. 22(3):311-315.

Lawrence, A. B., Petherick, J. C., McLean, K. A., Deans, L. A., Chirnside, J., Vaughan, A., Clutton, E. and Terlouw, E.M.C. 1994. The effect of environment on behaviour, plasma cortisol and prolactin on parturient sows. Appl. Anim. Behav. Sci. 39:313-330

Marianne O. Larsen and Bidda Roline. 2004. Use of the Göttingen minipig as a model of diabetes with special focus on type 1 diabetes research. ILAR Journal. 45(3):303-313.

Reese, D. E., Hartsock, T. G. and Morrow, W. E. M. 2001. Pork industry handbook. Perdue university cooperative extension service. PHI-18.

Vieuille-Thomas, C., Le Pape, G. and Signoret, J. P. 1995. Stereotypies in pregnant sows: indications of influence of housing system on the patterns expressed by the animals. Appl. Anim. Behav. Sci. 44:19-27.

Wiepkema, P. R. 1987. Developmental aspects of motivated behavior in domestic animals. J. Anim. Sci. 65:1220-1227.

(접수일자 : 2009. 12. 14/수정일자: 2010. 1. 18/ 채택일자 : 2010. 1. 20) 